\title{
Microcirculation and atherothrombotic parameters in prolactinoma patients: a pilot study
}

\author{
Anne Q. Reuwer · Brigitte M. Sondermeijer $\cdot$ Suzanne Battjes $\cdot$ Rogier van Zijderveld \\ Danka J. F. Stuijver · Peter H. Bisschop - Marcel Th. B. Twickler • \\ Joost C. M. Meijers $\cdot$ Reinier O. Schlingemann $\cdot$ Erik S. Stroes
}

Published online: 13 October 2011

(C) The Author(s) 2011. This article is published with open access at Springerlink.com

\begin{abstract}
Atherothrombosis is a multifactorial process, governed by an interaction between the vessel wall, hemodynamic factors and systemic atherothrombotic risk factors. Recent in vitro, human ex vivo and animal studies have implicated the hormone prolactin as an atherothrombotic mediator. To address this issue, we evaluated the anatomy and function of various microvascular beds as well as
\end{abstract}

Anne Q. Reuwer and Brigitte M. Sondermeijer contributed equally to this manuscript and the work related to it.

A. Q. Reuwer $(\bowtie)$ - B. M. Sondermeijer · S. Battjes ·

D. J. F. Stuijver - J. C. M. Meijers - E. S. Stroes

Department of Vascular Medicine, Academic Medical Center,

Room F4-145 Meibergdreef 9, 1105 AZ Amsterdam,

The Netherlands

e-mail: A.Q.Reuwer@amc.uva.nl

R. van Zijderveld

Department of Ophthalmology, Onze Lieve Vrouwe Gasthuis,

Amsterdam, The Netherlands

D. J. F. Stuijver

Department of Internal Medicine, Slotervaart Hospital,

Amsterdam, The Netherlands

P. H. Bisschop

Department of Endocrinology, Academic Medical Center,

Amsterdam, The Netherlands

M. Th. B. Twickler

Department of Endocrinology, Diabetology and Metabolic

Diseases, University Hospital Antwerp, Antwerp, Belgium

J. C. M. Meijers

Department of Experimental Vascular Medicine, Academic

Medical Center, Amsterdam, The Netherlands

R. O. Schlingemann

Department of Ophthalmology, Academic Medical Center,

Amsterdam, The Netherlands plasma atherothrombosis markers in patients with elevated prolactin levels. In this pilot study, involving 10 prolactinoma patients and 10 control subjects, sidestream dark field (SDF) imaging revealed a marked perturbation of the sublingual microcirculation in prolactinoma patients compared to control subjects, as attested to by significant changes in microvascular flow index $(2.74 \pm 0.12$ vs. $2.91 \pm 0.05$, respectively; $P=0.0006)$, in heterogeneity index $(0.28$ [IQR 0.18-0.31] vs. 0.09 [IQR 0.08-0.17], respectively; $P=0.002)$ and lower proportion of perfused vessels $(90 \pm$ $4.0 \%$ vs. $95 \pm 3.0 \%$, respectively; $P=0.016$ ). In the retina, fluorescein angiography (FAG) confirmed these data, since prolactinoma patients more often have dilatated perifoveal capillaries. In plasma, prolactinoma patients displayed several pro-atherogenic disturbances, including a higher endogenous thrombin potential and prothrombin levels as well as decreased HDL-cholesterol levels. Prolactinoma patients are characterized by microvascular dysfunction as well as plasma markers indicating a pro-atherothrombotic state. Further studies are required to assess if prolactin is causally involved in atherothrombotic disease.

Keywords Prolactinoma - Microcirculation · Coagulation · Inflammation $\cdot$ Atherothrombosis

\section{Introduction}

Atherothrombosis, the basis of cardiovascular disease, results from a complex interplay of hemodynamic changes, coagulation changes, inflammatory activation as well as changes in vessel wall function and structure [1, 2]. Various endocrine hormones have been suggested to be associated with an increased risk of cardiovascular disease (CVD) [3]. Although prolactin was originally identified as 
a lactotrophic hormone, it has recently also been shown to exert a variety of functions, potentially relevant for atherothrombotic disease [4]. This has led to the concept that prolactin may be a causal factor contributing to a proatherothrombotic state [3, 5].

In fact, prolactin has been shown to elicit an inflammatory response characterized by infiltration of lymphocytes, macrophages and neutrophils in vitro, as well as adhesion of circulating mononuclear cells to the endothelium; events which are involved in the biology of atherothrombosis [6-8]. Furthermore, the prolactin receptor was found to be present in macrophages of atherosclerotic plaques predominantly at sites characterized by a marked inflammatory response [5]. Several animal studies reported that prolactin promotes angiogenesis and has vasoconstrictive effects [9-12].

In the present study, we set out to explore whether prolactin has the ability to modulate microcirculatory function, inflammation and coagulation in humans. In addition to the investigation of the retinal and sublingual microvasculature, a panel of pro-atherothrombotic plasma markers in prolactinoma patients and healthy age- and sexmatched controls were also studied.

\section{Methods}

Patients and study design

The investigators obtained approval from the Institutional Review Board of the Academic Medical Center of Amsterdam and all participants provided written informed consent. The study was registered in the Netherlands Trial Register (NTR2511). The research adhered to the tenets set forth in the Declaration of Helsinki.

Patients were included in the study if a pituitary mass was visible on an MRI scan with gadolinium and venous plasma prolactin levels were exceeding $40 \mu \mathrm{g} / \mathrm{l}$. We arbitrarily choose this cut-off level, since we aimed to evaluate the effects of an active microprolactinoma. Exclusion criteria were: macroprolactinoma, if on dopamine-agonist and it was not appropriate to discontinue this for 8 weeks, other hormonal disturbances (such as polycystic ovary syndrome or thyroid disease), diabetes mellitus, pregnancy, overt vascular disease, anti-psychotic medication, anti-hypertensive medication or statins, any disease which could interfere with the retinal and/or sublingual vasculature, allergy or hypersensitivity to fluorescein or iodide, retinopathy, renal disease, active or previous cancer. Figure 1 illustrates the flow of patients through the selection process.

Consecutive outpatients who had undergone repetitive blood testing for prolactin levels to evaluate the persistency of elevated serum prolactin between November 1998 and
January 2010 and who were not on a dopamine agonist at the moment of blood withdrawal, were potentially eligible for this study $(\mathrm{n}=199)$. Of these patients, the majority had prolactin levels $<40 \mu \mathrm{g} / \mathrm{l}(\mathrm{n}=113)$. Additionally, consecutive outpatients with prolactin levels $>40 \mu \mathrm{g} / 1$ measured between February-December 2010 were potentially eligible as well, based on their prolactin level $(n=61)$. Two patients, ages younger than 18 years, were excluded. From these two groups, a total of 145 patients were potentially eligible. Their treating physician was contacted about the study regarding the in- and exclusion criteria, leading to assessment of eligibility based on the patient charts.

In twenty cases, the treating physician found the patients eligible based on the in- and exclusion criteria and did not have any objections against participation in the study. Eleven patients were invited for the screening visit, of which ten were eventually included. In the initial screening visit, two of the ten patients were on a dopamine-agonist and were requested to stop with the medication for 8 weeks until the next study visit. Furthermore, six patients with a microprolactinoma responded to our advertisement in a quarterly magazine of the Dutch Pituitary Foundation (Nederlandse Hypofyse Stichting). However, none of these six patients were eligible to come for a screening visit. In addition to the exclusion criteria, controls were recruited through advertisement and matched to patients according to sex and age (within 5 years of the date of birth of the corresponding patient). Participants refrained from alcohol and caffeine $12 \mathrm{~h}$ before participation in the study. During medical screening, blood pressure was measured and physical examination was performed. Blood (for analysis of parameters as shown in Tables 1 and 2) was drawn between 8 and 10 a.m. after an overnight fast.

\section{Biochemical variables}

Prolactin was measured by a solid-phase, two-site, timeresolved fluoroimmunometric assay (Delfia Prolactin, Wallac Oy, Turku, Finland) with a limit of detection of $1.0 \mathrm{mg} / \mathrm{l}$. The intra-assay coefficient of variation (CV) was $4-6 \%$, interassay $\mathrm{CV}$ was $5.5-7.2 \%$, with reference values for plasma prolactin $4.0-25.0 \mu \mathrm{g} / \mathrm{l}$ in women and $0.5-19.0 \mu \mathrm{g} / 1$ in men [13]. If prolactin levels were enhanced, polyethylene glycol (PEG) was used to precipitate macroprolactin. Total cholesterol, high density lipoprotein-cholesterol (HDL-C), and triglycerides were determined enzymatically (Boehringer Mannheim, Mannheim, Germany), and the interassay and intra-assay coefficients of variation $(\mathrm{CV})$ were $2 \%$ for all three. LDL-C was calculated using the Friedewald equation. Apolipoprotein B-100 (apoB-100) and apoA-I were assayed by rate nephelometry ( $\mathrm{CV}<5 \%$ for both). HsCRP was measured 


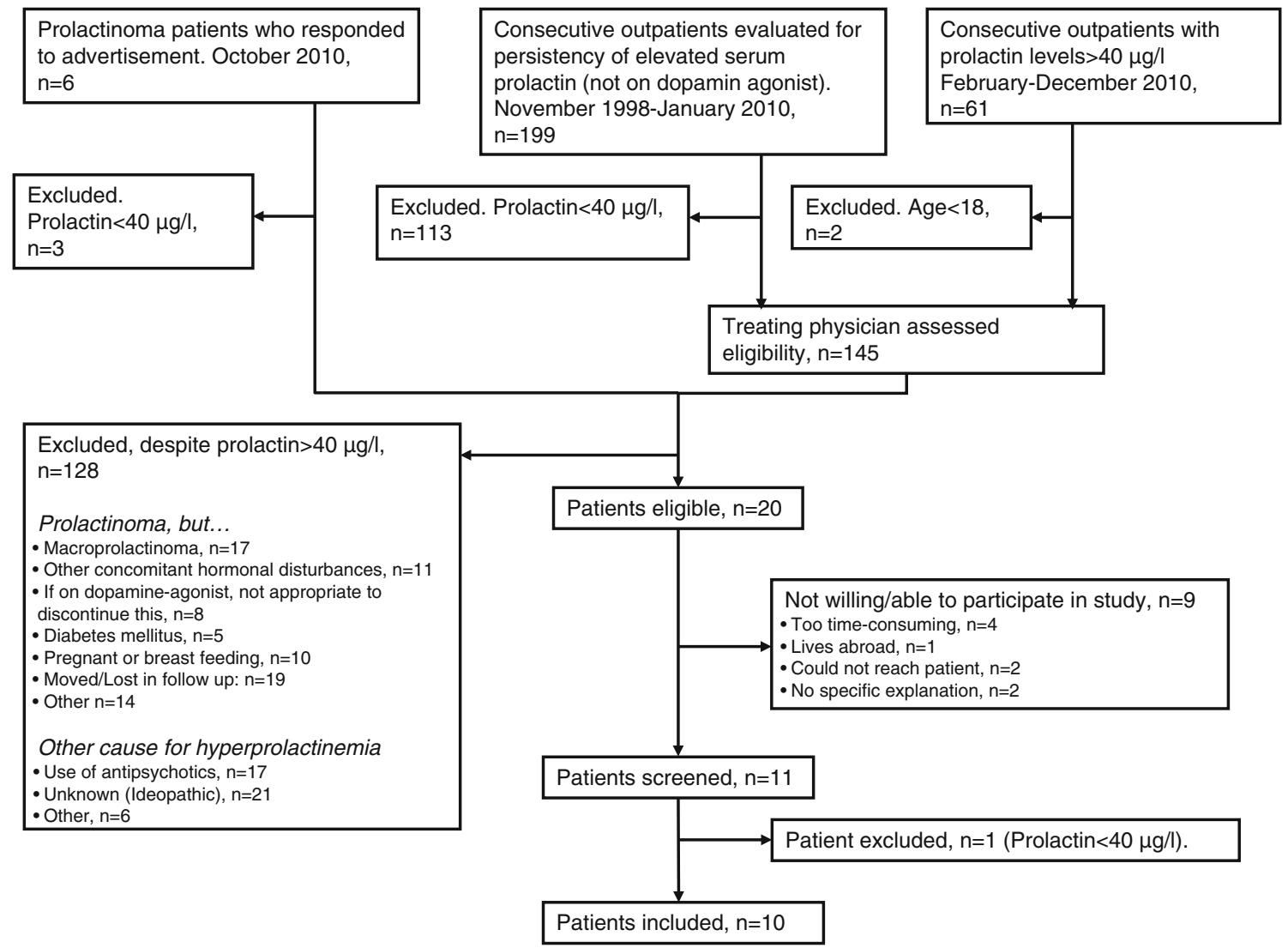

Fig. 1 Flow of patients in selection procedure

Table 1 Basic characteristics of prolactinoma patients and controls

Data are presented as median (IQR) or number (\%).

* $P<0.01$, ** $P<0.001$

$B M I$ body mass index, $H D L$ high density lipoprotein, $L D L$ low density lipoprotein, $A p o B$ apolipoprotein B

\begin{tabular}{lll}
\hline & Prolactinoma Patients $(\mathrm{n}=10)$ & Healthy controls $(\mathrm{n}=10)$ \\
\hline Current age (years) & $35(28-45)$ & $31(27-51)$ \\
Gender, male & $2(20 \%)$ & $2(20 \%)$ \\
Current smoking & $2(20 \%)$ & $2(20 \%)$ \\
BMI visit $\left(\mathrm{kg} / \mathrm{m}^{2}\right)$ & $25.6(21.2-29.8)$ & $22.6(21.3-24.4)$ \\
Waist circumference males $(\mathrm{cm})$ & $92(83-100)$ & $89(82-95)$ \\
Waist circumference females $(\mathrm{cm})$ & $96(78-103)$ & $84(75-94)$ \\
Systolic blood pressure $(\mathrm{mm} \mathrm{Hg})$ & $119(114-128)$ & $125(112-141)$ \\
Diastolic blood pressure $(\mathrm{mm} \mathrm{Hg})$ & $77(72-80)$ & $75(71-81)$ \\
Prolactin $(\mu \mathrm{g} / \mathrm{l})$ & $68(53-94)$ & $10.3(8.6-13.8)^{* *}$ \\
Oral contraceptives & $1(10 \%)$ & $3(30 \%)$ \\
Hemoglobin $(\mathrm{mmol} / \mathrm{l})$ & $8.1(7.5-8.8)$ & $8.3(7.8-8.8)$ \\
Leukocytes $\left(10^{\mathrm{E}} 9 / \mathrm{l}\right)$ & $5.8(4.4-6.8)$ & $5.0(3.8-7.2)$ \\
Platelets $\left(10^{\mathrm{E}} 9 / \mathrm{l}\right)$ & $247(194-300)$ & $259(229-306)$ \\
Glucose $(\mathrm{mmol} / \mathrm{l})$ & $4.7 \pm 0.4$ & $4.9(4.7-5.1)$ \\
Insulin $(\mathrm{pmol} / \mathrm{l})$ & $43(17-69)$ & $15(10-38)$ \\
Total cholesterol $(\mathrm{mmol} / \mathrm{l})$ & $4.4(4.1-5.7)$ & $4.9(4.7-5.5)$ \\
HDL-cholesterol $(\mathrm{mmol} / \mathrm{l})$ & $1.4(1.1-1.5)$ & $1.8(1.6-2.2)^{*}$ \\
LDL-cholesterol $(\mathrm{mmol} / \mathrm{l})$ & $2.6(2.2-3.7)$ & $2.7(2.3-3.3)$ \\
Triglyceride $(\mathrm{mmol} / \mathrm{l})$ & $1.0(0.7-1.5)$ & $1.0(0.5-1.2)$ \\
ApoB $(\mathrm{g} / \mathrm{l})$ & $0.8(0.7-11)$ & $0.7(0.7-0.9)$ \\
\hline
\end{tabular}


Table 2 Inflammatory and coagulation characteristics of prolactinoma patients and controls

\begin{tabular}{lll}
\hline & Prolactinoma patients $(\mathrm{n}=10)$ & Healthy controls $(\mathrm{n}=10)$ \\
\hline HsCRP $(\mathrm{mg} / \mathrm{l})$ & $2.9(0.6-5.0)$ & $0.8(0.6-2.8)$ \\
$\mathrm{TNF} \alpha(\mathrm{pg} / \mathrm{ml})[<10]$ & $3.0(3.0-3.0)$ & $3.0(3.0-3.0)$ \\
$\mathrm{IL}-6(\mathrm{pg} / \mathrm{ml})[<20]$ & $1.1(0.6-1.5)$ & $0.6(0.5-1.0)$ \\
D-dimer $(\mu \mathrm{g} / \mathrm{ml})[<1.00]$ & $0.5 \pm 0.1$ & $0.5 \pm 0.2$ \\
PT $(\mathrm{s})[10.7-12.9]$ & $10.7 \pm 0.6$ & $10.8 \pm 0.4$ \\
APTT $(\mathrm{s})[25.0-38.0]$ & $29.1 \pm 2.4$ & $28.7 \pm 2.5$ \\
Plasmin-antiplasmin complex $(\mathrm{ng} / \mathrm{ml})[47-563]$ & $338 \pm 104$ & $466 \pm 248$ \\
Antithrombin [86-139] & $110 \pm 8$ & $107 \pm 15$ \\
Protrombin fragment 1 $+2(\mathrm{pmol} / \mathrm{l})[53-271]$ & $157 \pm 38$ & $168 \pm 73$ \\
ETP $(\mathrm{nmol} / \mathrm{l} \times$ min) [1155-2606] & $2251 \pm 384$ & $1775 \pm 256^{*}$ \\
Prothrombin $(\mathrm{U} / \mathrm{dl})[80-130]$ & $130 \pm 21$ & $102 \pm 11^{*}$ \\
vWF ag $(\%)[50-150]$ & $114 \pm 34$ & $134 \pm 33$ \\
Factor VIII $(\%)[63-173]$ & $138 \pm 34$ & $141 \pm 40$ \\
Protein C activity $(\%)[70-120]$ & $114 \pm 14$ & $120 \pm 20$ \\
Protein S free \% [63-137] & $100 \pm 21$ & $104 \pm 28$ \\
\hline
\end{tabular}

Data are presented as mean $\pm \mathrm{SD}$ or median (IQR). $* P<0.01$

$H s C R P$ high sensitive CRP, TNF $\alpha$ Tumor necrosis factor $\alpha, I L-6$ Interleukin-6, $P T$ prothrombin time, APTT activated partial thromboplastin time, ETP endogenous thrombin potential, $v W F$ von Willebrand Factor

Normal range values are in "[ ]"

by a high-sensitivity method (Roche Diagnostic Corp., Basel, Switzerland) and (in case hsCRP $>10 \mathrm{mg} / \mathrm{ml}$ ) by immunonephelometry (P800 analyzer; Roche Diagnostic Corp.) $(\mathrm{CV}<4 \%)$.

Coagulation assays (prothrombin time [PT], activated partial thromboplastin time [APTT], prothrombin, factor VIII), D-dimer and antithrombin were determined on an automated coagulation analyzer (Behring Coagulation System, BCS) with reagents and protocols from the manufacturer (Siemens Healthcare Diagnostics, Marburg, Germany). Measurements of prothrombin fragment F1 + 2 (Siemens Healthcare Diagnostics), von Willebrand factor antigen (vWFag, antibodies from Dako, Glostrup, Denmark), Tumor necrosis factor $\alpha$ (TNF, Sanquin, Amsterdam, the Netherlands), interleukin-6 (IL-6, Sanquin), and plasmin- $\alpha 2$-antiplasmin complexes (PAP, DRG, Marburg, Germany) were performed by ELISA. Protein $\mathrm{C}$ was determined using the Coamatic protein $\mathrm{C}$ activity kit from Chromogenix (Mölndal, Sweden). Free protein $\mathrm{S}$ was measured by precipitating the $\mathrm{C} 4 \mathrm{~b}$-binding protein-bound fraction with polyethylene glycol 8,000 and measuring the concentration of free protein $\mathrm{S}$ in the supernatant by ELISA using antibodies from Dako (Glostrup, Denmark).

The endogenous thrombin potential was determined as described by Hemker et al. [14] and the Thrombinoscope manual (Thrombinoscope BV, Maastricht, The Netherlands). Coagulation was triggered by recalcification in the presence of $5 \mathrm{pM}$ recombinant human tissue factor
(Innovin, Siemens Healthcare Diagnostics), $4 \mu \mathrm{M}$ phospholipids, and $417 \mu \mathrm{M}$ fluorogenic substrate Z-Gly-GlyArg-AMC (Bachem, Bubendorf, Switzerland). Fluorescence was monitored using a Fluoroskan Ascent fluorometer (ThermoLabsystems, Helsinki, Finland), and the ETP was calculated using Thrombinoscope software (Maastricht, The Netherlands).

Sublingual microvascular network

Local sublingual microcirculation was visualized using sidestream dark field (SDF) imaging technology (Microscan Video Microscope System, MicroVision Medical, Amsterdam, The Netherlands); details on this technique have been described elsewhere [15]. All imaging was performed using a $5 \times$ magnifying objective lens system which was in turn captured by a video camera with a $720 \times 576$ pixel resolution, resulting in a $1.0 \times 0.75 \mathrm{~mm}$ imaged tissue segment. All measurements were recorded on a Canon MV730i digital video recorder.

The optical probe, covered with a sterile cap (Microscan Lens, MicroVision Medical, Amsterdam, The Netherlands) was gently applied to the sublingual mucosa. Clips at five sublingual sites yielding at least $10 \mathrm{~s}$ of stable video per site were recorded. Special care was taken to avoid pressure artifacts, adhering to the standard operating procedure previously described by Trzeciak et al. [15] also recommended in the round table conference [16]. Clips were 
analyzed off-line with the aid of a validated software package (Cap-Image, Dr. H. Zeintl Engineering, Heidelberg, Germany) [17] in random fashion by a single investigator who was unaware of the study hypothesis and blinded to diagnosis.

Microvascular flow index was used to quantify microvascular blood flow. In this score, each frame was divided in four quadrants and per quadrant flow was characterized as absent (0), intermittent (1), sluggish (2), or normal (3) [18]. Each participant's values obtained from the mucosa fields were averaged. To assess flow heterogeneity between the different areas investigated, we used the heterogeneity index. The latter was calculated as the highest site flow velocity minus the lowest site flow velocity, divided by the mean flow velocity of all sublingual sites in that participant [15]. The capillary density was calculated similar to the technique of De Backer et al. [16]. A grid of equidistant vertical and horizontal lines was superimposed on the image. The vessel density was calculated as the number of small vessels $(<20 \mu \mathrm{m})$ intersecting the lines of the grid divided by the total length of the lines yielding the number of small vessels per mm. Perfused capillary density was calculated by multiplying capillary density by the proportion of perfused capillaries. The proportion of perfused capillaries was then calculated as follows: $100 \times$ [(total number of vessels $<20 \mu \mathrm{m}$ without flow)/total number of vessels] [16].

\section{Retinal microvascular network}

FAG was performed at the retina unit of the Department of Ophthalmology of the Academic Medical Center. Patients received an injection of fluorescein sodium $(500 \mathrm{mg}$ per individual; Fresenius Kabi, 's Hertogenbosch, The Netherlands) in their left antecubital vein. Standard fundus photography and fluorescein angiography employing a TopCon TRCA50 fundus camera (TopCon Inc., Japan) and IMAGEnet-i-Base Imaging Software (TopCon Inc., Japan) were used to evaluate the retinal and choroidal vasculature. The presence of dilatated vessels around the fovea (absent, moderate or severe) was assessed. Analyses were conducted in a randomised fashion by an ophthalmologist blinded to the status of the participant.

\section{Statistical analysis}

Results are presented as mean $\pm \mathrm{SD}$ or median (interquartile range). Differences between prolactinoma patients and controls were tested using a Student's $t$ test (two-sided, equal variances, unpaired) when the results were normally distributed, and Mann-Whitney test otherwise. Differences in dichotomous variables between groups were analyzed by $\chi^{2}$ test. We used SPSS software, version 16.0 (Chicago, IL,
USA) and GraphPad Prism Software version 5.0 (CA, USA). Associations between prolactin and the various microcirculatory parameters were assessed using univariate linear regression (prolactin and the heterogeneity index were log-transformed since both variables were not-normally distributed). The correlation between dilatation of perifoveal arteries and patients was calculated applying the Fisher exact test. Results were stratified according to outcome (absent, moderate or severe). A probability value $(P)<0.05$ was considered to confer statistical significance.

\section{Results}

\section{Clinical characteristics and biochemistry}

Clinical characteristics of the participants are shown in Table 1. Blood count was comparable between the two groups. As expected, prolactin levels in prolactinoma patients were higher than in control participants (68.0 [IQR 53-94] $\mu \mathrm{g} / \mathrm{l}$ vs. 10.3 [IQR 8.6-13.8] $\mu \mathrm{g} / \mathrm{l}, P<0.001$ ). Prolactinoma patients also showed higher body mass indexes (25.6 [IQR $21.2-29.8] \mathrm{kg} / \mathrm{m}^{2}$ in patients vs. 22.6 [IQR 21.3-24.4] $\mathrm{kg} / \mathrm{m}^{2}$ in controls, $P=0.02$ ) and we found a trend towards higher insulin levels (43 [IQR 17-69] $\mathrm{pmol} / 1$ vs. 15 [IQR 10-38] pmol/1 in controls, $P=0.06)$. With the exception of lower HDL-C levels in patients (1.4 [IQR 1.1-1.5] mmol/l vs. 1.8 [IQR 1.6-2.2] $\mathrm{mmol} / \mathrm{l}$ in controls, $P=0.02$ ), no other differences between groups were observed for lipid parameters (total cholesterol, low-density-cholesterol, triglycerides, apolipoprotein B).

Haemostatic and inflammatory parameters are listed in Table 2. Increased plasma prothrombin was found in patients $(130 \pm 21 \mathrm{U} / \mathrm{dl}$ in patients vs. $102 \pm 11 \mathrm{U} / \mathrm{dl}$ in controls, $P=0.0015$ ). In line, the endogenous thrombin potential was $36 \%$ higher in prolactinoma patients compared to controls $(2251 \pm 384 \mathrm{nmol} / \mathrm{l} \times$ min vs. $1,775 \pm$ $256 \mathrm{nmol} / 1 \times \mathrm{min}, \quad P=0.0061)$. No differences were observed for other procoagulant parameters between patients and controls. Also, no differences were found for the tested fibrinolytic parameters. IL- 6 showed a trend towards an increase in prolactinoma patients (1.1 [IQR $0.6-1.5] \mathrm{pg} / \mathrm{ml}$ in cases vs. 0.6 [IQR $0.5-1.0] \mathrm{pg} / \mathrm{ml}$ in controls, $P=0.09$ ). In reminiscence of this observation, hsCRP showed a trend towards increased levels in patients as well (2.9 [IQR 0.6-5.0] in patients vs. 0.8 [IQR $0.6-2.8] \mathrm{mg} / \mathrm{l}$ in controls, $P=0.17$ ).

Microvascular network assessed with SDF and FAG

Microvascular flow index (MFI) was significantly lower in prolactinoma patients compared to controls $(2.74 \pm 0.12$ 

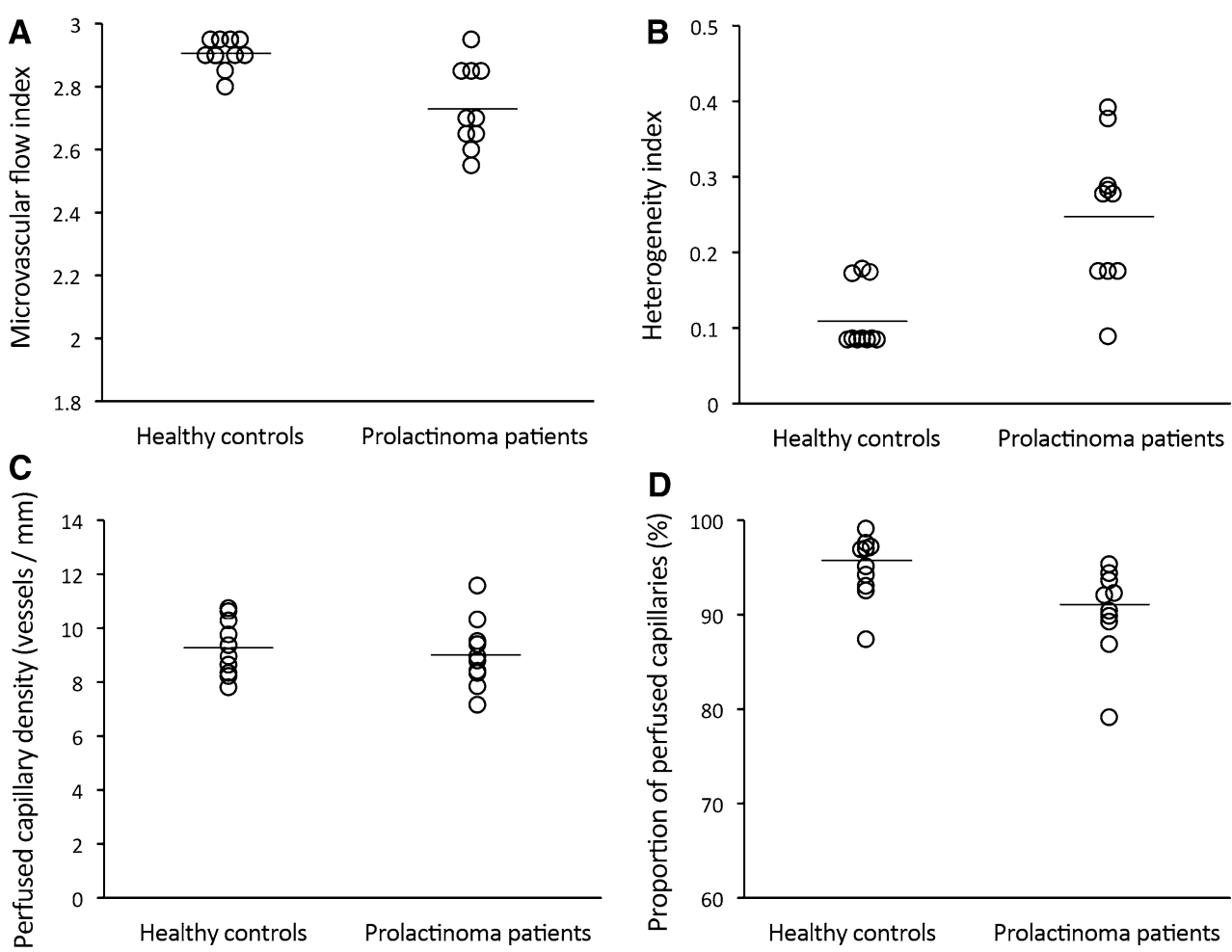

Fig. 2 a Microvascular flow index (MFI). In this score, each frame was divided in four quadrants and per quadrant flow was characterised as absent (0), intermittent (1), sluggish (2), or normal (3). For each participant, values obtained from the five mucosa fields were averaged. Prolactinoma patients show decreased microcirculatory flow velocity score in comparison to healthy subjects $(2.74 \pm 0.12$ vs. $2.91 \pm 0.05$, respectively; $P=0.0006$ ). Linear regression analysis showed a significant relation between levels of prolactin and MFI; $\beta-0.028$; [95\% CI -0.045 to -0.012 ]; $P=0.002$ ). b Flow heterogeneity index (FHI) was calculated as the highest site flow velocity minus the lowest site flow velocity, divided by the mean flow velocity of all sublingual sites in that patients had a higher FHI in comparison to controls $(0.28$ [IQR 0.18-0.31] vs. 0.09 [IQR 0.08-0.17]; $P=0.002$ ). Linear regression analysis demonstrated a significant relation between levels of prolactin and FHI; $\beta$ 0.320; [95\% CI 0.110-0.530]; $P=0.005$ ).

vs. $2.91 \pm 0.05$, respectively; $P=0.0006$ ) (Fig. 2a). Linear regression analysis showed a significant relation between levels of prolactin and MFI; $\beta-0.028$; (95\% CI -0.045 to -0.012$) ; P=0.002$. In addition, patients had a higher flow heterogeneity index (FHI) compared to controls (0.28 [IQR 0.18-0.31] vs. 0.09 [IQR 0.08-0.17], respectively; $P=0.002$ ) (Fig. 2b). Also, linear regression analysis demonstrated a significant relation between levels of prolactin and FHI; $\beta$ 0.320; [95\% CI $0.110-0.530$ ]; $P=0.005)$. There was no difference in perfused capillary density between the two groups $(9.04 \pm 1.20$ vessels $/ \mathrm{mm}$ in prolactinoma patients versus $9.23 \pm 1.03$ vessels $/ \mathrm{mm}$ in healthy controls, $P=0.71$ ) (Fig. 2c). Prolactinoma patients also had a lower proportion of perfused capillaries (PPC; $90 \pm 4.0 \%$ vs. $95 \pm 3.0 \%$, respectively; $P=0.016$;

c Perfused capillary density in prolactinoma patients and controls was calculated by multiplying capillary density by the proportion of perfused capillaries. The proportion of perfused capillaries was calculated as follows: $100 \times$ [(total number of vessels $<20 \mu \mathrm{m}$ without flow)/total number of vessels]. There was no difference in perfused capillary density between the two groups $(9.04 \pm 1.20$ vessels $/ \mathrm{mm}$ in prolactinoma patients vs. $9.23 \pm 1.03$ vessels $/ \mathrm{mm}$ in healthy controls, $P=0.71)$. d The proportion of perfused capillaries (PPC) in prolactinoma patients and healthy controls. PPC was calculated as follows: $100 \times$ [(total number of vessels $<20 \mu \mathrm{m}$ without flow)/total number of vessels]. Compared with controls, individuals suffering from prolactinoma had a lower proportion of perfused capillaries $(90 \pm 4.0 \%$ vs. $95 \pm 3.0 \%$, respectively; $P=0.016$ ). Indeed, linear regression analysis showed a significant relation between levels of prolactin and PPC; $\beta-0.056 ;[95 \% \mathrm{CI}-0.098 ;-0.014] ; P=0.012)$

Fig. 2d). Indeed, linear regression analysis showed a significant relation between levels of prolactin and PPC; $\beta-0.056$; [95\% CI -0.098 to -0.014 ]; $P=0.012$ ). In line, prolactinoma patients more often displayed dilatated vessels around the fovea as assessed with FAG $(P=0.05)$ (Table 3).

\section{Discussion}

In the present study, we show evidence that prolactinoma patients are characterized by thrombotic and pro-inflammatory plasma changes, as well as signs of microvascular dysfunction, indicative of a pro-atherothrombotic state. 
Table 3 Retinal microvascular network assessed with FAG

\begin{tabular}{lcl}
\hline & $\begin{array}{l}\text { Prolactinoma } \\
\text { patients }(\mathrm{n})\end{array}$ & $\begin{array}{l}\text { Healthy } \\
\text { individuals }(\mathrm{n})\end{array}$ \\
\hline $\begin{array}{l}\text { Dilatated vessels around } \\
\text { the fovea }\end{array}$ & & \\
Absent & 1 & 6 \\
Moderate & 4 & 2 \\
Severe & 5 & 2 \\
Total & 10 & 10 \\
\hline
\end{tabular}

Fisher's exact $P=0.05$

Biochemistry: hemostasis (procoagulant, anticoagulant and fibrinolytic parameters)

Thrombin generation is a pivotal function of plasma in hemostasis, which plays a role in the onset of acute cardiovascular events. The endogenous thrombin potential (ETP), i.e. the area under the thrombin generation curve, is a marker for the capacity of plasma to generate thrombin following a pathophysiological stimulus. Therefore, ETP may also be useful to assess bleeding- or thrombotic risk $[19,20]$. Prothrombin conversion which is carried out by factor Xa, with a velocity that is determined by the availability of factor $\mathrm{Va}$ and the surface of a procoagulant membrane, all contribute to thrombin generation [19]. Two major findings in haemostatic parameters in our group of prolactinoma patients comprised a higher prothrombin concentration and elevated ETP levels. Higher prothrombin concentration in prolactinoma patients results from enhanced prothrombin synthesis or decreased clearance of prothrombin in these individuals. In this respect, Nishino et al. [21] showed that prolactin enhanced the sensitivity of liver microsomes to vitamin $\mathrm{K}$ in rats, resulting in enhanced prothrombin synthesis. Whereas prothrombin fragment $1+2$ levels were not increased, the plasma of prolactinoma patients had a higher capacity to generate thrombin upon activation of coagulation. These observations suggest that prolactinoma patients may have an increased risk of venous and/or arterial thrombosis.

D-dimer levels and the fibrinolytic system (as assessed by determination of plasmin- $\alpha 2$-antiplasmin complexes) did not differ between prolactinoma patients and controls, indicating that fibrinolysis was not influenced by the presence of hyperprolactinemia. Von Willebrand factor (vWF), an accepted marker of endothelial damage/dysfunction, did not differ between groups.

In earlier studies, Karmali et al. [22] showed that prolactin shortened bleeding time. In accordance, Erem et al. [23] reported an increased platelet count, fibrinogen and tissue plasminogen activator inhibitor-1 (PAI-1) levels in prolactinoma patients, compatible with a hypercoagulable and hypofibrinolytic state. In contrast, antithrombin levels were also increased, indicating enhanced anticoagulant activity [23]. These equivocal data leave the role and underlying mechanisms of hemostasis as a link between prolactin and cardiovascular risk unresolved.

Biochemistry: systemic inflammation

Prolactin has been acknowledged to elicit inflammatory responses by inducing leukocyte activation [24]. In the present study, we observed a trend towards elevated IL-6 levels in prolactinoma patients, which has been shown to contribute to atherosclerotic plaque development as well as plaque destabilisation by a variety of mechanisms [25]. Concordantly, IL-6 is a powerful predictor of future cardiovascular events in high-risk patients [26]. A recent study corroborated that prolactin levels correlated with IL- 6 in normoprolactinemic patients [27]. Mechanistically, previous studies have indicated that prolactin induces IL-6 release from macrophages in mice [28]. The latter may also explain the increased IL-6 levels in prolactinoma patients.

A direct interaction between high prolactin and BMI is uncertain, since both higher [29] as well as similar BMIs [30] have been reported for prolactinoma patients in comparison to controls. Similar inconsistencies have been reported for lipid profiles, ranging from overt hypercholesterolemia and hypertriglyceridemia [23, 31-33] to normal lipid profiles in prolactinoma patients $[29,30]$. The low HDL-C levels in our patient group may relate to systemic inflammation, as attested to by the trend towards higher Il-6 and CRP levels [34]. Waist circumference was not different between the groups, which is of relevance since central adiposity-related indicators are known to correlate with plasma pro-inflammatory markers [35].

\section{Microcirculation}

Microcirculatory perturbations have been suggested to contribute to the development of atherothrombotic events $[36,37]$. In the present study, we show that the sublingual microcirculation is disturbed in prolactinoma patients compared to healthy individuals, indicated by a lower microcirculatory flow index, higher heterogeneity index and lower proportion of perfused capillaries. In addition, prolactinoma patients more often displayed dilatation of the vessels around the fovea compared to the control subjects. Interestingly, choroidal blood flow is increased above control in diabetic subjects with moderate to severe diabetic retinopathy [38]. Thus, the dilatation of the vessels in the fovea in the prolactinoma patients may at least be nonbeneficial.

Previously it was shown that microvascular reactivity in the finger, measured with laser Doppler fluximetry was not correlated with physiological prolactin levels [39]. To our 
knowledge, this is the first study to assess the microcirculation in patients with pathologically elevated levels of prolactin. Under these circumstances, high prolactin levels may have an adverse effect on the vessel wall. In fact, prolactin receptors were shown to be present on endothelial cells [40]. In accordance, Molinari et al. showed that prolactin-induced vasoconstriction through inhibition of a vasodilatory beta(2)-adrenergic receptor-mediated effect related to reduced NO availability [12]. Prolonged exposure to high prolactin levels may also alter the vascular smooth muscle cell layer through stimulating smooth muscle cell proliferation [41]. Changes in vascular diameter of arterioles depend for a larger part on the contractile activation in vascular smooth muscle cells [42]. Since vasoconstriction leads to lower microcirculatory flow [43], we propose that prolactin-induced vasoconstriction may lead to the diminished microcirculatory flow index we observed.

Because the retinal and cerebral small vessels share similar embryological origins and structural [44] and physiological characteristics (the blood-retinal and bloodbrain barriers) [45], the retinal vasculature can be a surrogate for cerebral small vasculature to study in vivo [46]. This concept is supported by findings from population based studies that retinal microvascular signs predict clinical stroke events [37] and stroke mortality [47]. It is tempting to speculate that our present findings may also have implications for the cerebral vasculature, which needs to be addressed in a separate study using other imaging modalities.

\section{Limitations}

This study has several limitations, which need closer attention. First, as indicated in Fig. 1, the included number of subjects is relatively small because most hyperprolactinemic patients did not fulfil the strict inclusion criteria. Therefore, our results may not be representative for all prolactinoma patients, since as can be extracted from Fig. 1, a lot of excluded patients suffered from macroprolactinomas, which needed acute treatment. Additionally many excluded patients had concomitant co-morbidities, or relatively low prolactin levels despite their microprolactinoma. Prolactinomas occur most frequently in females aged between 20 and 50 years, whilst the ratio between the sexes is estimated to be 10 to 1 (women to men) [48], which is reflected in our study population. Indeed, this study is limited by its case-control design and only allows exploration of associations, and no causality is implied.

Additionally, fasting insulin levels are higher in prolactinoma patients, suggesting a propensity towards insulin resistance. Indeed, others showed that these patients are characterized by a decreased insulin sensitivity in response to euglycemic hyperinsulinemic clamps [33]. Furthermore, hyperprolactinemia due to prolactinoma results in low estrogen and low progesterone levels. Thus, apart from the observed difference in HDL-C levels, the propensity towards insulin resistance and the gonadotrophic state in prolactinoma patients may have partly contributed to the observed differences in coagulation and inflammatory markers between cases and controls. The use of oral contraconceptives could have affected these parameters; however, since this use was lower in prolactinoma patients than in healthy individuals, any confounding effect in this matter is highly unlikely. Nevertheless, previous studies provide mechanistic evidence that prolactin has the ability to directly influence prothrombin synthesis [21] and leukocyte function [24], thereby providing a link between prolactin and the pro-atherothrombotic phenotype.

In summary, this pilot study indicates that prolactinoma patients exhibit signs of atherotrombosis, i.e. marked perturbation of the microcirculation and biochemical markers indicative of a pro-inflammatory and procoagulant state. Therefore, prolactin may contribute to the pathogenesis of atherothrombosis. However, further studies are needed to assess if prolactin is indeed causally involved in atherothrombotic disease and whether prolactinoma patients are at increased cardiovascular risk.

Acknowledgments We would like to express our gratitude to the prolactinoma patients and the healthy control subjects for their participation in this study and to Monique Wezel, Christa Jansen, Dick de Vries and Annette Hover for their help at the retina unit of the Department of Ophthalmology of the Academic Medical Center. We are grateful to personnel of the Dpts. of Experimental Vascular Medicine and Endocrinology of the Academic Medical Center for help in laboratory analyses. Th. B. Twickler $(\mathrm{MD}, \mathrm{PhD})$ is supported by the Netherlands Organization of Health and Science (NWO-ZonMW; project number 916.66.124).

Conflict of interest The funding sources had no role in study design, conduct analysis and decision to submit the manuscript for publication. Nothing to disclose.

Open Access This article is distributed under the terms of the Creative Commons Attribution Noncommercial License which permits any noncommercial use, distribution, and reproduction in any medium, provided the original author(s) and source are credited.

\section{References}

1. Lusis AJ (2000) Atherosclerosis. Nature 407:233-241

2. Lee KW, Lip GY (2003) Acute coronary syndromes: Virchow's triad revisited. Blood Coagul Fibrinolysis 14:605-625

3. van Zaane B, Reuwer A, Büller H, Kastelein J, Gerdes V, Twickler M (2009) Hormones and cardiovascular disease: a shift in paradigm with clinical consequences? Semin Thromb Hemost 35:478-487

4. Ben-Jonathan N, LaPensee CR, LaPensee EW (2008) What can we learn from rodents about prolactin in humans? Endocr Rev 29:1-41 
5. Reuwer AQ, van Eijk M, Houttuijn-Bloemendaal FM, van der Loos CM, Claessen N, Teeling P, Kastelein JJP, Hamann J, Goffin V, von der Thusen JH, Twickler M, Aten J (2011) The prolactin receptor is expressed in macrophages within human carotid atherosclerotic plaques: a role for prolactin in atherogenesis? J Endocrinol 208:107-117

6. Chavez-Rueda K, Hérnandéz J, Zenteno E, Leaños-Miranda A, Legorreta-Haquet MV, Blanco-Favela F (2005) Identification of prolactin as a novel immunomodulator on the expression of costimulatory molecules and cytokine secretions on $\mathrm{T}$ and $\mathrm{B}$ human lymphocytes. Clin Immunol 116:182-191

7. Montes de Oca P, Macotela Y, Nava G, Lopez-Barrera F, de la Escalera GM, Clapp C (2005) Prolactin stimulates integrinmediated adhesion of circulating mononuclear cells to endothelial cells. Lab Invest 85:633-642

8. Levi M, van der Poll T, Buller HR (2004) Bidirectional relation between inflammation and coagulation. Circulation 109:2698-2704

9. Grosdemouge I, Bachelot A, Lucas A, Baran N, Kelly P, Binart N (2003) Effects of deletion of the prolactin receptor on ovarian gene expression. Reprod Biol Endocrinol 1:12

10. Ko JY, Ahn YL, Cho BN (2003) Angiogenesis and white blood cell proliferation induced in mice by injection of a prolactinexpressing plasmid into muscle. Mol Cells 15:262-267

11. Struman I, Bentzien F, Lee H, Mainfroid V, D'Angelo G, Goffin V, Weiner RI, Martial JA (1999) Opposing actions of intact and $\mathrm{N}$-terminal fragments of the human prolactin/growth hormone family members on angiogenesis: an efficient mechanism for the regulation of angiogenesis. Proc Natl Acad Sci USA 96:1246-1251

12. Molinari C, Grossini E, Mary DASG, Uberti F, Ghigo E, Ribichini F, Surico N, Vacca G (2007) Prolactin induces regional vasoconstriction through the beta\}2-adrenergic and nitric oxide mechanisms. Endocrinology 148:4080-4090

13. Le Moli R, Endert E, Fliers E, Mulder T, Prummel MF, Romijn JA, Wiersinga WM (1999) Establishment of reference values for endocrine tests II: hyperprolactinemia. Neth J Med 55:71-75

14. Hemker HC, Giesen P, Al Dieri R, Regnault V, de Smedt E, Wagenvoord R, Lecompte T, Béguin S (2003) Calibrated automated thrombin generation measurement in clotting plasma. Pathophysiol Haemost Thromb 33:4-15

15. Trzeciak S, Dellinger RP, Parrillo JE, Guglielmi M, Bajaj J, Abate NL, Arnold RC, Colilla S, Zanotti S, Hollenberg SM (2007) Early microcirculatory perfusion derangements in patients with severe sepsis and septic shock: relationship to hemodynamics, oxygen transport, and survival. Ann Emerg Med 49: $88-98$

16. De Backer D, Hollenberg S, Boerma C, Goedhart P, Büchele G, Ospina-Tascon G, Dobbe I, Ince C (2007) How to evaluate the microcirculation: report of a round table conference. Crit Care 11:R101

17. Klyscz T, Jünger M, Jung F, Zeintl H (1997) Cap image-a new kind of computer-assisted video image analysis system for dynamic capillary microscopy. Biomed Tech (Berl) 42:168-175

18. Spronk PE, Ince C, Gardien MJ, Mathura KR, Straaten HMO, Zandstra DF (2002) Nitroglycerin in septic shock after intravascular volume resuscitation. Lancet 360:1395-1396

19. Hemker HC, Béguin S (1995) Thrombin generation in plasma: its assessment via the endogenous thrombin potential. Thromb Haemost 74:134-138

20. Hemker HC, Al Dieri R, De Smedt E, Béguin S (2006) Thrombin generation, a function test of the haemostatic-thrombotic system. Thromb Haemost 96:553-561

21. Nishino Y (1979) Hormonal control of prothrombin synthesis in rat liver microsomes, with special reference to the role of estradiol, testosterone and prolactin. Arch Toxicol Suppl 2:397-402

22. Karmali RA, Horrobin DF (1975) Letter: prolactin, bromocriptine, and haemostasis. Br Med J 3:307
23. Erem C, Kocak M, Nuhoglu I, Yilmaz M, Ucuncu O (2010) Blood coagulation, fibrinolysis and lipid profile in patients with prolactinoma. Clin Endocrinol 73:502-507

24. Dorshkind K, Horseman ND (2000) The Roles of Prolactin, Growth Hormone, Insulin-Like Growth Factor-I, and Thyroid Hormones in Lymphocyte Development and Function: Insights from Genetic Models of Hormone and Hormone Receptor Deficiency. Endocr Rev 21:292-312

25. Schuett H, Luchtefeld M, Grothusen C, Grote K, Schieffer B (2009) How much is too much? Interleukin-6 and its signalling in atherosclerosis. Thromb Haemost 102:215-222

26. Nishida H, Horio T, Suzuki Y, Iwashima Y, Tokudome T, Yoshihara F, Nakamura S, Kawano Y (2011) Interleukin-6 as an independent predictor of future cardiovascular events in high-risk Japanese patients: comparison with C-reactive protein. Cytokine 53:342-346

27. Friedrich N, Schneider HJ, Spielhagen C, Markus MRP, Haring R, Grabe HJ, Buchfelder M, Wallaschofski H, Nauck M (2011) The association of serum prolactin concentration with inflammatory biomarkers-cross-sectional findings from the population-based Study of Health in Pomerania. Clinical Endocrinology 2011 (Epub ahead of print)

28. Zellweger R, Zhu XH, Wichmann MW, Ayala A, De Maso CM, Chaudry IH (1996) Prolactin administration following hemorrhagic shock improves macrophage cytokine release capacity and decreases mortality from subsequent sepsis. J Immunol 157: $5748-5754$

29. Serri O, Li L, Mamputu JC, Beauchamp MC, Maingrette F, Renier G (2006) The influences of hyperprolactinemia and obesity on cardiovascular risk markers: effects of cabergoline therapy. Clin Endocrinol 64:366-370

30. Yavuz D, Deyneli O, Akpinar I, Yildiz E, Gozu H, Sezgin O, Haklar G, Akalin S (2003) Endothelial function, insulin sensitivity and inflammatory markers in hyperprolactinemic premenopausal women. Eur J Endocrinol 149:187-193

31. Heshmati HM, Turpin G, de Gennes JL (1987) Chronic hyperprolactinemia and plasma lipids in women. Klin Wochenschr 65:516-519

32. Pelkonen R, Nikkilä EA, Grahne B (1982) Serum lipids, postheparin plasma lipase activities and glucose tolerance in patients with prolactinoma. Clin Endocrinol (Oxf) 16:383-390

33. Berinder K, Nyström T, Höybye C, Hall K, Hulting AL (2010) Insulin sensitivity and lipid profile in prolactinoma patients before and after normalization of prolactin by dopamine agonist therapy. Pituitary 3:199-207

34. Haas MJ, Mooradian AD (2010) Regulation of high-density lipoprotein by inflammatory cytokines: establishing links between immune dysfunction and cardiovascular disease. Diabetes Metab Res Rev 26:90-99

35. Hermsdorff H, Zulet M, Puchau B, Martínez JA (2011) Central adiposity rather than total adiposity measurements are specifically involved in the inflammatory status from healthy young adults. Inflammation 34:161-170

36. Reaven PD, Emanuele N, Moritz T, Klein R, Davis M, Glander K, Duckworth W, Abraira C (2008) Proliferative diabetic retinopathy in type 2 diabetes is related to coronary artery calcium in the veterans affairs diabetes trial (VADT). Diabetes Care 31:952-957

37. Wong TY, Klein R, Couper DJ, Cooper LS, Shahar E, Hubbard LD, Wofford MR, Sharrett AR (2001) Retinal microvascular abnormalities and incident stroke: the atherosclerosis risk in communities study. Lancet 358:1134-1140

38. Savage HI, Hendrix JW, Peterson DC, Young H, Wilkinson CP (2004) Differences in pulsatile ocular blood flow among three classifications of diabetic retinopathy. Invest Ophthalmol Vis Sci 45:4504-4509 
39. Georgiopoulos GA, Stamatelopoulos KS, Lambrinoudaki I, Lykka M, Kyrkou K, Rizos D, Creatsa M, Christodoulakos G, Alevizaki M, Sfikakis PP, Papamichael C (2009) Prolactin and preclinical atherosclerosis in menopausal women with cardiovascular risk factors. Hypertension 54:98-105

40. Ricken AM, Traenkner A, Merkwitz C, Hummitzsch K, Grosche J, Spanel-Borowski K (2007) The short prolactin receptor predominates in endothelial cells of micro- and macrovascular origin. J Vasc Res 44:19-30

41. Sauro MD, Zorn NE (1991) Prolactin induces proliferation of vascular smooth muscle cells through a protein kinase C-dependent mechanism. J Cell Physiol 148:133-138

42. Hirano K, Hirano M, Kanaide H (2004) Regulation of myosin phosphorylation and myofilament $\mathrm{Ca} 2+$ sensitivity in vascular smooth muscle. J Smooth Muscle Res 40:219-236

43. Segal SS (2005) Regulation of blood flow in the microcirculation. Microcirculation 12:33-45

44. Delaey C, Van de Voorde J (2000) Regulatory mechanisms in the retinal and choroidal circulation. Ophthalmic Res 32:249-256
45. Patton N, Aslam T, MacGillivray T, Pattie A, Deary IJ, Dhillon B (2005) Retinal vascular image analysis as a potential screening tool for cerebrovascular disease: a rationale based on homology between cerebral and retinal microvasculatures. J Anat 206: 319-348

46. Bosch MM, Merz TM, Barthelmes D, Petrig BL, Truffer F, Bloch KE, Turk A, Maggiorini M, Hess T, Schoch OD, Hefti U, Sutter FK, Pichler J, Huber A, Landau K (2009) New insights into ocular blood flow at very high altitudes. J Appl Physiol 106:454-460

47. Mitchell P, Wang JJ, Wong TY, Smith W, Klein R, Leeder SR (2005) Retinal microvascular signs and risk of stroke and stroke mortality. Neurology 65:1005-1009

48. Colao A, Sarno AD, Cappabianca P, Briganti F, Pivonello R, Somma CD, Faggiano A, Biondi B, Lombardi G (2003) Gender differences in the prevalence, clinical features and response to cabergoline in hyperprolactinemia. Eur $\mathrm{J}$ Endocrinol 148: $325-331$ 